\title{
Validity Evidence of the Brazilian Version of the Five Facet Mindfulness Questionnaire (FFMQ) ${ }^{1}$
}

\author{
Víviam Vargas de Barros ${ }^{2}$ \\ Universidade Federal de Juiz de Fora \\ Elisa Harumi Kozasa \\ Hospital Israelita Albert Einstein \\ Universidade Federal de São Paulo \\ Isabel Cristina Weiss de Souza \\ Universidade Federal de São Paulo \\ Telmo Mota Ronzani \\ Universidade Federal de Juiz de Fora
}

\begin{abstract}
In order to assess the psychometric properties of the Brazilian version of the FFMQ, 395 participants divided into smokers, people from the general population, college students, and meditators answered the FFMQ and the Psychological Well-Being Scale (PWBS). An Exploratory Factor Analysis (EFA) was conducted and the reliability was assessed. The FFMQBR consists of seven factors and all of them showed good internal consistency. Evidence of the construct and criterion validity was obtained by a significant correlation between the FFMQ-BR scores and well-being and by a significant difference between the scores of the meditators and the other participants on the FFMQ-BR. This study may help in providing subsidies to the progress of research in the topic by examining the empirical relationships between Mindfulness and mental health.
\end{abstract}

Keywords: mindfulness, Brazil, FFMQ

\section{Evidências de Validade da Versão Brasileira do Questionário das Cinco Facetas de Mindfulness (FFMQ-BR)}

\begin{abstract}
RESUMO - Com o objetivo de avaliar as propriedades psicométricas da versão brasileira do FFMQ, 395 participantes divididos entre tabagistas, comunidade geral, universitários e meditadores responderam ao FFMQ e à Escala de Bem-Estar Subjetivo (EBES). Foi realizada uma Análise Fatorial Exploratória (AFE) e a avaliação da fidedignidade. O FFMQ-BR foi composto por sete facetas e todas obtiveram valores adequados de consistência interna. Comprovou-se a validade de construto e de critério através da correlação entre os escores do FFMQ-BR e a EBES e da diferença entre os escores dos meditadores e dos demais participantes no FFMQ-BR, respectivamente. Estes resultados podem fornecer subsídios para o avanço das pesquisas nessa área através da avaliação enpírica de relações entre mindfulness e saúde mental.
\end{abstract}

Palavras-chave: Mindfulness, Brasil, FFMQ

Although the concept of mindfulness is derived from ancient Buddhist traditions, the use of this concept as a form of health intervention brought the need to define mindfulness in psychological terms (Baer, 2011). Thus, according to the purposes of this study, the concept of mindfulness that will be used follows the concepts of Western psychology in which mindfulness refers to a metacognitive skill defined by Jon Kabat-Zinn as "paying attention in a particular way, on purpose, in the present moment and nonjudgmentally" (Kabat-Zinn, 1990).

Through sustained practice of mindfulness, it is possible to develop skills to calmly move away from thoughts and

1 Aknowledgements: The authors would like to thank Leonardo Fernandes Martins for statistical support and the Fundação de Amparo à Pesquisa do Estado de Minas Gerais (FAPEMIG), Coordenação de Aperfeiçoamento de Pessoal de Nível Superior (CAPES) and Centro Nacional de Desenvolvimento Científico e Tecnológico (CNPq) for financial support.

2 Endereço para correspondência: Rua José Lourenço Kelmer s/n, Bairro São Pedro. Departamento de Psicologia, Instituto de Ciências Humanas, Universidade Federal de Juiz de Fora, Juiz de Fora, MG, Brasil, CEP: 36036-900.E-mail:viviamvb@yahoo.com.br emotions during stressful events rather than engage in anxious concerns or other negative thought patterns that may be the beginning of a stress reactivity cycle and contribute to increase psychological stress (Teasdale, Segal, \& Williams, 1995).

As far as the mechanisms of action of mindfulness-based interventions are concerned, Hölzel et al. (2011) proposed a recent model that includes four steps which interact in a chronological order: attention regulation, body awareness, emotion regulation, and change in perspective on the self. The authors hypothesize that when a stimulus triggers an emotional reaction, the executive system tries to regulate attention as an attempt to remain in a mindful state. Body awareness detects physiological signals that show the emotional response to the stimulus. The processes of emotion regulation helps prevent hyper-learned habitual reactions. This response prevention leads to the extinction of hyperlearned behaviors and to the reconsolidation of the self when mindfulness is practiced in the long term.

Similarly, Witkiewitz, Marlatt and Walker (2005) state that the major contributions of the mindfulness practice are the development of awareness, the acceptance of thoughts, 
feelings and other mental events, and the use of those abilities as an effective strategy in coping with difficult and high risk situations.

The skills developed by the practice of mindfulness allow practitioners to be able to reduce negative affect and increase positive affect, thereby increasing the psychological wellbeing (PWB) (Schroevers \& Brandsma, 2010). Studies have associated higher levels of mindfulness with higher positive affect, life satisfaction, and self-esteem, and lower negative affect and rumination (Shapiro, Oman, Thoresen, Plante, \& Flinders, 2008).

In addition to their influence on the subjective well-being, mindfulness-based interventions have shown great efficacy for different types of mental disorders and chronic diseases, including chronic pain (Morone, Lynch, Greco, Tindle, \& Weiner, 2008) and primary insomnia (Gross et al., 2011). They have also proved effective in improving the quality of life of cancer patients (Carlson, Speca, Patel, \& Goodey, 2004), reducing anxiety in patients with heart conditions (Tácon, McComb, Caldera, \& Randolph, 2003), and reducing mood disorders (Williams, 2008). Moreover, many positive physiological changes are reported in the literature as a result of mindfulness practice. An example is the increase in the variability of heart rate associated with better performance of the autonomomic nervous system (Nesvold et al., 2012). In addition, a recent review about mindfulness and substance abuse shows that those interventions might reduce craving and the use of several substances (Chiesa \& Serretti, 2014).

Although the studies on mindfulness are growing, the topic is still incipient, particularly in Brazil. Moreover, there is a need to better understand how mindfulness-based interventions work and for whom they serve. This will be possible through the development of valid and reliable instruments that measure mindfulness and its components, as well as, associations between them and clinical changes (Didonna, 2009).

Therefore, the relevance of this study is to generate evidence of validity of the Five Facet Mindfulness Questionnaire (FFMQ) (Baer, Smith, Hopkins, Krietemeyer, \& Toney, 2006), which measures levels of mindfulness in a multidimensional way.

Several current descriptions of mindfulness suggest its multidimensional nature. For example, in the Dialectical Behavior Therapy (DBT) (Dimidjian \& Linehan, 2003), mindfulness is conceptualized as having six elements, three related to what one does when being mindful (observing, describing, and participating) and three related to how one does it (nonjudgmentally, one-mindfully, and effectively). Segal, Williams and Teasdale (2002) summarized the nature of mindfulness by stating:

In mindfulness practice, the focus of a person's attention is opened to admit whatever enters experience, while at the same time, a stance of kindly curiosity allows the person to investigate whatever appears, without falling prey to automatic judgments or reactivity. (p. 322-323).This description suggests several elements, including observation of present-moment experience, acceptance, nonjudging, and nonreactivity.
Scanning technologies have been used to investigate the brain of meditators to search for evidence of neurobiological changes related to the practice mindfulness meditation (Baer, 2011). Many controlled studies with encouraging results have been published. They point to an association between mindfulness practice and changes in the activation of specific brain areas as the prefrontal cortex (PFC) and the anterior cingulate cortex (ACC) (Chiesa \& Serretti, 2010).

Some researches have pointed to an association between training in mindfulness and improvement in working memory and sustained attention. This finding corroborates the hypothesis that those practices can potentially have a long-term impact on the brain and the human behavior. In this sense, results show that the increase in the level of mindfulness is proportional to the frequency of daily meditation practice (Baer, 2011; Lutz, Slagter, Dunne, \& Davidson, 2008).

The way meditation practice enhances the levels of mindfulness in daily routine and why those practices are beneficial can only be clarified through the use of instruments that measure those mindfulness levels and assess how much they differ between individuals who meditate and those who do not (Baer, 2011). Therefore, it is essential that instruments, which have this measuring potential be developed, adapted and validated.

Among the commonly used scales designed to assess mindfulness are the Freiburg Mindfulness Inventory - FMI; Mindful Attention Awareness Scale - MAAS; Kentucky Inventory of Mindfulness Skills - KIMS; Cognitive and Affective Mindfulness Scale - CAMS and Mindfulness Questionnaire - MQ. These scales were used by Baer et al. (2006) for the preparation of FFMQ, which also sought to establish the psychometric properties of this new measure. To build an instrument that measures different facets of mindfulness, the authors gathered all of the items from the questionnaires above, resulting in 112 items. The sample consisted of 613 college students, who responded to those items. Then, the items were subjected to EFA and correlational analysis.

The analysis revealed a structure with five factors. These findings suggested that mindfulness can be conceptualized as a multifaceted construct consisting of several related skills. Observing is the tendency to notice or attend to internal and external experiences. Describing involves labeling observed experiences with words. Acting with awareness refers to paying attention to ongoing activity and is often contrasted with behaving mechanically while attention is focused elsewhere (often called automatic pilot). Nonjudging of inner experience involves taking a nonevaluative stance toward cognitions and emotions. Nonreactivity to inner experience is the tendency to allow feelings and thoughts to come and go without getting carried away by or caught up in them (Baer et al., 2006).

To compose the final scale, the authors included the seven items from the facet, "Nonreactivity to inner experience," and selected the eight items with the highest factor loadings for 
each of the other facets composing a final pool of 39 items (Baer et al., 2006).

Besides the FFMQ, the authors used other scales to assess the correlation between the facets of mindfulness and other constructs, such as, openness to experience, alexithymia, emotional intelligence, subjective well-being, among others, to assess the construct validity of FFMQ. All correlations were in the expected direction indicating that the FFMQ showed convergent and discriminant validity with other related constructs.

The FFMQ was selected because it is one of the most cited instruments to assess mindfulness. The choice for the FFMQ was based on the review of the scientific literature, once this instrument is one of the most cited measures to assess mindfulness (Sauer et al., 2013). In addition, the FFMQ was adapted and validated in at least six countries to date being able to measure levels of mindfulness in a wide range of populations with or without meditation experience (Baer et al., 2008; Cebolla et al., 2012; Dundas, Vøllestad, Binder \& Sivertsen, 2013; Hou, Wong, Lo, Mak, \& Ma, 2013; Sugiura, Sato, Ito, \& Murakami, 2012; Tran, Glück, \& Nader, 2013; Veehof, Klooster, Taal, Westerhof, \& Bohlmeijer, 2011).

The overall objective of this study was to translate, adapt and present evidence of validity of the Five Facet Mindfulness Questionnaire (FFMQ-BR) for the Brazilian reality among a population from the general community, people who meditate regularly, college students, and tobacco smokers.

\section{Method}

\section{Participants}

This study had a convenience sample that comprised of: 1) smokers $(n=97)$, who entered the specialized treatment service in the month of the data collection; 2) general community participants, who were selected on a primary health care unit $(n=123) ; 3)$ college students $(n=139)$ and 4) people who meditate regularly at least three times a week for at least one year $(n=36)$, selected at a meditation retreat in the city of Viamão in Rio Grande do Sul - Brazil. The diversity of the sample allowed us to assess the adequacy of the scale in people with different levels of meditative practice and education. All participants were over eighteen years.

The sample consisted of 395 participants defined by the proportion of 10 participants per item of the instrument (Hair, Anderson, Thatan, \& Black, 2005). Among all the participants, 50 from the group of college students also participated in the retest. For the analysis of criterion validity,

Table 1. Description of the demographics of the participants $(n=395) *$.

\begin{tabular}{|c|c|c|c|c|}
\hline Variables & $\begin{array}{c}\text { Smokers } \\
n(\%)\end{array}$ & $\begin{array}{l}\text { UAPS } \\
n(\%)\end{array}$ & $\begin{array}{l}\text { UFJF } \\
n(\%)\end{array}$ & $\begin{array}{c}\text { Meditators } \\
n(\%)\end{array}$ \\
\hline \multicolumn{5}{|l|}{ Gender } \\
\hline Female & $63(64.9)$ & $95(77.2)$ & $113(81.3)$ & $22(61.1)$ \\
\hline Male & $34(35.1)$ & $28(22.8)$ & $26(18.7)$ & $14(38.9)$ \\
\hline \multicolumn{5}{|l|}{ Age } \\
\hline$\leq 25$ & $4(4.2)$ & $7(5.8)$ & $126(90.6)$ & \\
\hline Between 26 and 44 & $28(29.5)$ & $31(25.6)$ & $12(8.6)$ & $20(55.6)$ \\
\hline Between 45 and 64 & $58(61.1)$ & $70(57.9)$ & $1(0.7)$ & $14(38.9)$ \\
\hline$\geq 65$ & $5(5.3)$ & $13(10.7)$ & & $2(5.6)$ \\
\hline \multicolumn{5}{|l|}{ Live with a partner } \\
\hline No & $60(63.2)$ & $52(42.3)$ & $132(95.0)$ & $24(70.6)$ \\
\hline Yes & $35(36.8)$ & $71(57.7)$ & $7(5.0)$ & $10(29.4)$ \\
\hline \multicolumn{5}{|l|}{ Family Income (minimum wages) } \\
\hline Up to 3 & $67(69.8)$ & $97(78.9)$ & $31(22.3)$ & $3(9.4)$ \\
\hline 3 to 6 & $20(20.8)$ & $21(17.1)$ & $51(36.7)$ & $6(18.8)$ \\
\hline 6 to 10 & $9(9.4)$ & $5(4.1)$ & $32(23.0)$ & $6(18.8)$ \\
\hline More than 10 & & & $25(18.0)$ & $17(53.1)$ \\
\hline \multicolumn{5}{|l|}{ Schooling } \\
\hline Up to elementary school & $40(41.2)$ & $62(50.4)$ & & \\
\hline Complete or incomplete high school & $36(37.1)$ & $44(35.8)$ & & $1(2.8)$ \\
\hline Complete or incomplete college & $21(21.6)$ & $17(13.8)$ & $139(100.0)$ & $35(97.2)$ \\
\hline
\end{tabular}

Note: * For some variables, the percentage is based in a smaller $\mathrm{n}$ because of data missing. 
three participants were included in the general community group in order to equate the groups.

The sample was mainly composed by women in all groups. Most of the participants were aged between 45 and 64 years old. In the students group, the ages varied from 18 to 25 years old. The family income and years of schooling were similar among tobacco users and primary care patients and was higher among the students and the experienced meditators (Table 1).

\section{Main Outcome Measures}

The research instruments were composed of structured and self-report questionnaires:

1. Socio-demographics. This was used for the characterization of the surveyed sample and included the following variables: age, sex, marital status, occupation, educational level, employment status, household income, and years of education.

2. Fagerström test for nicotine dependence. It was used as an eligibility criterion for the study. Consists of a six-question questionnaire and assesses the degree of nicotine dependence $(\alpha=0.64)$ (Carmo \& Pueyo, 2002).

3. Five Facet Mindfulness Questionnaire (FFMQ). Scale that assesses the level of mindfulness composed by 39 items on a of 5-point Likert scale ranging from 1 (never or rarely true) to 5 (almost always or always true). On this scale the concept of mindfulness is divided into five components: a) Observe; b) Describe; c) Acting with awareness; d) Nonjudgement of inner experience; and e) Nonreactivity to inner experience (Baer et al., 2006).

4. Subjective Well-Being Scale (SWBS). The SWBS is composed of 62 items. The first 47 items are divided into two factors that describe positive and negative affect. The participant answers how he has been feeling lately in a 5-point Likert scale ranging from "not at all" to "extremely." Both these factors have Cronbach's alpha $=0.95$. The Negative Affect factor has inverted items, which means that high scores on this factor refer to low level of negative affect.. In the second part of the scale, the items range from numbers 48 to 62 composing the third scaling factor "life satisfaction", and describe judgments concerning the evaluation of "satisfaction" or "dissatisfaction with life" in a 5-point Likert scale ranging from "strongly disagree" to "strongly agree" $(\alpha$ = 0.90) (Albuquerque \& Tróccoli, 2004).

\section{Procedures}

This study was divided into two phases. The first phase consisted on the process of translation and cultural adaptation of the instrument. The second was marked by the study of the psychometric properties of the instrument verifying the indicators of validity and reliability of the instrument. It is worth mentioning that Ruth A. Baer, the first author of the FFMQ, authorized the adaptation and validation of the instrument before conducting this study.
In the first phase, the process of translation and cultural adaptation of the instrument was performed, following the standardized five steps: 1) two translations; 2) synthesis; 3) two back translations; 4) committee of experts and 5) pre-test (Beaton, Bombardier, Guillemin, \& Ferraz, 2002).

This initial process does not guarantee that the instrument translated and adapted is trustworthy and reliable. A second phase is required and aimed at verifying the psychometric qualities of the instrument (Beaton et al., 2002). To do so, the adapted instrument was applied in groups with each group of participants described above. Participants completed the questionnaires in a private room. They were administered in one session of approximately one hour. Questionnaire completion was preceded by explanations given by the researchers who followed the test manual procedures for the selected instruments. This second phase assessed the criterion and construct validity and the reliability of the FFMQ-BR. The analysis used for these evaluations are described below.

\section{Data Analysis}

The data were entered by two typists in a database of the SPSS ${ }^{\circ}$, version 15.0. The two versions underwent a comparison through the Epi Info 3.5.3, module Data Compare, to detect any typing errors.

Data were analyzed by descriptive and inferential statistics. Descriptive statistics was used to characterize the sample through the mean, median, standard deviation, and frequency for the nominal and ordinal variables.

For the inferential analysis, we adopted a significance level of $5 \%$ for all statistical tests $(\mathrm{p}<0.05)$.

\section{Evidence of construct validity}

To elucidate the construct validity of FFMQ-BR, we performed an EFA on the correlation matrix of the items with factor extraction through the method of principal components without rotation, in order to identify the multidimensionality of the scale, as well as, for the verification of its possible facets. We adopted the factor loading of 0.4 for the maintenance of the items on the scale.

We also calculated the correlations between total scores of the FFMQ-BR and PWBS considering the bivariate Spearman test to the scores that did not show a normal distribution and Pearson for normally distributed scores. In addition, we calculated the correlations between each facet of FFMQ-BR with each factor of the Psychological WellBeing Scale.

To further evaluate content overlap among the facets of FFMQ-BR, we performed a multiple regression analysis. In this analysis we considered separately each of the facets as the dependent variable with the other facets as the predictors. Using the method described in the original validation paper (Baer et al., 2006), the value of adjusted $\mathrm{R}^{2}$ represents the variance in each facet explained by its relationship with the others. Subtracting the values of adjusted $\mathrm{R}^{2}$ from the Cronbach's alpha of each facet, we obtained the systematic variance of the facet, regardless of their relationship with the 
others. The smaller this value, the greater the content overlap among the facets.

\section{Evidence of criterion validity}

Criterion validity was analyzed by comparing the scores of meditators and the other participants in the FFMQ-BR in order to assess whether there was a significant difference between them. Therefore, we used the independent samples t-test for the cases with a normal distribution of data and the Mann-Whitney test for cases with non-normal distribution.

\section{Reliability}

The reliability analysis was performed using the internal consistency estimated by Cronbach's alpha coefficient and test-retest estimated by Pearson Linear Correlation Coefficient.

\section{Ethical aspects}

This study was approved by the Research Ethics Committee of the Universidade Federal de Juiz de Fora (Opinion Document number 120/2011, consistent with the Resolution CNS number 196/96). Each participant received a Statement of Informed Consent in which the research objectives were explained.

\section{Results}

After completion of the translation and cultural adaptation, we decided to maintain the original name translated to Portuguese and the original acronym followed by the letters "BR" to maintain the international reference for publications and to facilitate the identification of the instrument to a national audience. The Brazilian version of the instrument was named the Facets of Mindfulness Questionnaire (FFMQ-BR).

The instructions for filling out the questionnaire remained the same with its literal translation. In the pre-test we could ensure that the questionnaire was understandable and kept the dimensions of the original items. Thus, we concluded the final version of the instrument that was used on the data collection in the second phase.

\section{Construct Validity - FFMQ-BR}

When performing the EFA of the FFMQ-BR, the structure of the scale was composed by nine factors. The first factor grouped the eight items correspondent to the "nonjudge" facet. The second factor grouped five items correspondent to the facet "act with awareness". The third factor correspondent to the "Observe" facet was comprised of six items. The fourth factor, which refers to the "describe" facet, grouped five items. The fifth factor related to the facet "describe" grouped only three items, items $12,16,22$ in the original scale. The items from the "nonreactivity" facet were grouped in the sixth factor. The seventh factor also grouped three items that corresponded to the items of the "Act with Awareness" facet in the original scale.

Items 9, 19, 21 and 36 were grouped in the eighth or the ninth factor, but we chose to keep them in the factors correspondent to its facets in the original scale once they added relevant content to the concept of mindfulness. Then, the item 36 was kept in the "observe" facet, where it achieved a factor loading equal to 0.2 . Items 9,19 , and 21 in the facet "nonreact" obtained factor loadings equal to $0.24,0.34$, and 0.21 , respectively. Besides these four items, the item 11 was grouped in the sixth factor, which we decided to keep it in its original facet "observe," where it obtained a factor loading equal to 0.34 .

It was observed that in FFMQ-BR, two facets of the original version were divided into other two facets: 1) "Describe," which was divided into one factor containing items with positive formulation (fourth factor) and one containing the items with negative formulation (fifth factor), and 2) "Act with Awareness," which was divided into a factor with items relating to act on autopilot (second factor) and one containing items related to act distractedly (seventh factor). The variance explained by each factor and their respective eigenvalues in brackets are described below from the first to the seventh factor. Factor 1 explained $15.03 \%$ of the total variance (5.86); Factor 2 accounted for $13.29 \%$ of the variance (5.18); Factor 3, 5.80\% of the variance $(2,26)$; Factor 4, explained $4.93 \%$ of the variance (1.92); Factor 5, $3.63 \%$ (1.41); Factor 6, 3.42\% (1.33); and finally Factor 7 accounted for $3.22 \%$ of the total variance (1.26). The seven factors structure explained $49.56 \%$ of the total variance (Table 2). KMO test resulted in .85 and the Bartlett's Test of Sphericity had an approximated Chi-Square of 4672.19 with $741 \mathrm{DF}$ and $\mathrm{p}<0,001$.

Evidence of construct validity of the FFMQ-BR was also confirmed through statistically significant correlations between total score and the scores of its facets and the total score of all the subscales of PWBS. As expected, the total score of FFMQ-BR correlated positively with all its facets and with the total score of PWBS and its factors $(p<0.001)$. The total score of PWBS showed the highest correlation with the total score of FFMQ-BR. The facet that had the strongest correlation with the total score of FFMQ-BR was "describe (positive)" (Table 3).

\section{Criterion Validity of the FFMQ-BR}

In order to find evidence of criterion validity of FFMQ$\mathrm{BR}$, we used a group of meditators and randomly selected participants with similar socio-demographics characteristics (i.e. gender, age, education, and household income) among the other groups to be compared with the meditators group. We conducted the chi-square test to compare groups and we found no significant difference in any of the sociodemographics variables. Thus, the sample used for the analysis of criterion validity was composed of 67 participants including the meditators and the other participants, mostly 
Tabela 2. Exploratory factor analysis of the 39 items from the FFMQ-BR $(n=395)$ *.

\begin{tabular}{|c|c|c|c|c|c|c|c|c|}
\hline \multirow{2}{*}{$\mathbf{N}^{\circ}$} & \multirow{2}{*}{ Items } & \multicolumn{7}{|c|}{ Factors } \\
\hline & & 1 & 2 & 3 & 4 & 5 & 6 & 7 \\
\hline & Nonjudge & & & & & & & \\
\hline 17 & I make judgments about whether my thoughts are good or bad & .71 & & & & & & \\
\hline 35 & $\begin{array}{l}\text { When I have distressing thoughts or images. I judge myself as good or } \\
\text { bad. depending what the thought/image is about }\end{array}$ & .68 & & & & & & \\
\hline 30 & $\begin{array}{l}\text { I think some of my emotions are bad or inappropriate and I shouldn't } \\
\text { feel them }\end{array}$ & .66 & & & & & & \\
\hline 14 & $\begin{array}{l}\text { I believe some of my thoughts are abnormal or bad and I shouldn’t } \\
\text { think that way }\end{array}$ & .64 & & & & & & \\
\hline 25 & I tell myself that I shouldn't be thinking the way I'm thinking & .59 & & & & & & \\
\hline 39 & I disapprove of myself when I have irrational ideas & .51 & & & & & & \\
\hline 3 & I criticize myself for having irrational or inappropriate emotions & .45 & & & & & & \\
\hline \multirow[t]{2}{*}{10} & I tell myself I shouldn't be feeling the way I'm feeling & .43 & & & & & & \\
\hline & Act with Awareness (automatic pilot) & & & & & & & \\
\hline 8 & $\begin{array}{l}\text { I don't pay attention to what I'm doing because I'm daydreaming. } \\
\text { worrying. or otherwise distracted }\end{array}$ & & .43 & & & & & \\
\hline 23 & $\begin{array}{l}\text { It seems I am "running on automatic" without much awareness of what } \\
\text { I'm doing }\end{array}$ & & .57 & & & & & \\
\hline 28 & I rush through activities without being really attentive to them & & .71 & & & & & \\
\hline 38 & I find myself doing things without paying attention & & .73 & & & & & \\
\hline \multirow[t]{2}{*}{34} & I do jobs or tasks automatically without being aware of what I'm doing & & .76 & & & & & \\
\hline & Observe & & & & & & & \\
\hline 20 & $\begin{array}{l}\text { I pay attention to sounds. such as clocks ticking. birds chirping. or cars } \\
\text { passing }\end{array}$ & & & .49 & & & & \\
\hline 1 & $\begin{array}{l}\text { When I'm walking. I deliberately notice the sensations of my body } \\
\text { moving }\end{array}$ & & & 67 & & & & \\
\hline 26 & I notice the smells and aromas of things & & & .69 & & & & \\
\hline 31 & $\begin{array}{l}\text { I notice visual elements in art or nature. such as colors. shapes. } \\
\text { textures. or patterns of light and shadow }\end{array}$ & & & .59 & & & & \\
\hline 15 & $\begin{array}{l}\text { I pay attention to sensations. such as the wind in my hair or sun on my } \\
\text { face }\end{array}$ & & & 69 & & & & \\
\hline 6 & $\begin{array}{l}\text { When I take a shower or bath. I stay alert to the sensations of water on } \\
\text { my body }\end{array}$ & & & .58 & & & & \\
\hline 36 & I pay attention to how my emotions affect my thoughts and behavior. & & & $.27 *$ & & & & \\
\hline \multirow[t]{2}{*}{11} & $\begin{array}{l}\text { I notice how foods and drinks affect my thoughts. bodily sensations. } \\
\text { and emotions }\end{array}$ & & & $.34 *$ & & & & \\
\hline & Describe (positive formulation items) & & & & & & & \\
\hline 27 & $\begin{array}{l}\text { Even when I'm feeling terribly upset. I can find a way to put it into } \\
\text { words }\end{array}$ & & & & .70 & & & \\
\hline 2 & I'm good at finding words to describe my feelings & & & & .72 & & & \\
\hline 37 & I can usually describe how I feel at the moment in considerable detail & & & & .43 & & & \\
\hline 32 & My natural tendency is to put my experiences into words & & & & .70 & & & \\
\hline 7 & I can easily put my beliefs. opinions. and expectations into words & & & & .58 & & & \\
\hline
\end{tabular}


Tabela 2. Exploratory factor analysis of the 39 items from the FFMQ-BR $(n=395) *$ Cont.

\begin{tabular}{|c|c|c|c|c|c|c|c|c|}
\hline \multirow{2}{*}{$\mathbf{N}^{\circ}$} & \multirow{2}{*}{ Items } & \multicolumn{7}{|c|}{ Factors } \\
\hline & & 1 & 2 & 3 & 4 & 5 & 6 & 7 \\
\hline & Describe (negative formulation items) & & & & & & & \\
\hline 22 & $\begin{array}{l}\text { When I have a sensation in my body. it's difficult for me to describe it } \\
\text { because I can't find the right words }\end{array}$ & & & & & .77 & & \\
\hline 12 & It's hard for me to find the words to describe what I'm thinking & & & & & .73 & & \\
\hline \multirow[t]{2}{*}{16} & $\begin{array}{l}\text { I have trouble thinking of the right words to express how I feel about } \\
\text { things }\end{array}$ & & & & & .64 & & \\
\hline & Nonreact & & & & & & & \\
\hline 33 & $\begin{array}{l}\text { When I have distressing thoughts or images. I just notice them and let } \\
\text { them go }\end{array}$ & & & & & & .63 & \\
\hline 4 & I perceive my feelings and emotions without having to react to them & & & & & & .47 & \\
\hline 24 & When I have distressing thoughts or images. I feel calm soon after & & & & & & .61 & \\
\hline 29 & $\begin{array}{l}\text { When I have distressing thoughts or images I am able just to notice } \\
\text { them without reacting }\end{array}$ & & & & & & .66 & \\
\hline 19 & $\begin{array}{l}\text { When I have distressing thoughts or images. I "step back" and am } \\
\text { aware of the thought or image without getting taken over by it }\end{array}$ & & & & & & $.34 *$ & \\
\hline 21 & In difficult situations. I can pause without immediately reacting & & & & & & $.21^{*}$ & \\
\hline \multirow[t]{2}{*}{9} & I watch my feelings without getting lost in them & & & & & & $.24 *$ & \\
\hline & Act with Awareness (distraction) & & & & & & & \\
\hline 18 & I find it difficult to stay focused on what's happening in the present & & & & & & & .52 \\
\hline 13 & I am easily distracted & & & & & & & .68 \\
\hline 5 & When I do things. my mind wanders off and I'm easily distracted & & & & & & & .70 \\
\hline
\end{tabular}

Note: * Items that we opted to maintain in its original facets despite its low factor loadings.

Table 3. Correlations between the total scores of the FFMQ-BR and its facets and the total score of the PWBS and its subscales $(n=395)$.

\begin{tabular}{|c|c|c|c|c|c|c|c|c|c|c|c|}
\hline \multirow{2}{*}{ Measures } & \multicolumn{3}{|c|}{ EBES } & \multicolumn{5}{|c|}{ FFMQ } & \multirow[b]{2}{*}{9} & \multirow[b]{2}{*}{10} & \multirow[b]{2}{*}{11} \\
\hline & 1 & 2 & 3 & 4 & 5 & 6 & 7 & 8 & & & \\
\hline 1. PWBS (Positive Affect) & 1.00 & & & & & & & & & & \\
\hline 2. PWBS (Negative Affect) & $0.50 * *$ & 1.00 & & & & & & & & & \\
\hline 3. Life Satisfaction & $0.60^{* *}$ & $0.63^{* *}$ & 1.00 & & & & & & & & \\
\hline 4. PWBS total & $0.81 * *$ & $0.88^{* *}$ & $0.83^{* *}$ & 1.00 & & & & & & & \\
\hline 5. FFMQ total & $0.49 * *$ & $0.51^{* *}$ & $0.40^{* *}$ & $0.56^{* *}$ & 1.00 & & & & & & \\
\hline 6. FFMQ (Nonjudge) & 0.07 & $0.28 * *$ & $0.24 * *$ & $0.24 * *$ & $0.43 * *$ & 1.00 & & & & & \\
\hline $\begin{array}{l}\text { 7. FFMQ (Actaware - } \\
\text { automatic pilot) }\end{array}$ & $0.25 * *$ & $0.41^{* *}$ & $0.30^{* *}$ & $0.39 * *$ & $0.60^{* *}$ & $0.36^{* *}$ & 1.00 & & & & \\
\hline 8. FFMQ (Observe) & $0.34 * *$ & $0.17^{* *}$ & $0.13^{*}$ & $0.25^{* *}$ & $0.50 * *$ & $-0.28 * *$ & 0.07 & 1.00 & & & \\
\hline 9. FFMQ (Describe - positive) & $0.42 * *$ & $0.26^{* *}$ & $0.24 * *$ & $0.36^{* *}$ & $0.67 * *$ & 0.02 & $0.26^{* *}$ & $0.40^{* *}$ & 1.00 & & \\
\hline $\begin{array}{l}\text { 10. FFMQ (Describe - } \\
\text { negative) }\end{array}$ & $0.19 * *$ & $0.29 * *$ & $0.20 * *$ & $0.28 * *$ & $0.50 * *$ & $0.31 * *$ & $0.44 * *$ & -0.08 & $0.40 * *$ & 1.00 & \\
\hline 11. FFMQ (Nonreact) & $0.32 * *$ & $0.25 * *$ & $0.20 * *$ & $0.31 * *$ & $0.56 * *$ & -0.07 & 0.05 & $0.51 * *$ & $0.33 * *$ & -0.04 & 1.00 \\
\hline $\begin{array}{l}\text { 12. FFMQ (Actaware - } \\
\text { distraction) }\end{array}$ & $0.30 * *$ & $0.36^{* *}$ & $0.27 * *$ & $0.37 * *$ & $0.53 * *$ & $0.29 * *$ & $0.51 * *$ & 0.03 & $0.21 * *$ & $0.34 * *$ & 0.05 \\
\hline
\end{tabular}


Tabela 4. Differences between the means of meditators and the other participants on the FFMQ $(n=67)$.

\begin{tabular}{|c|c|c|c|c|c|c|c|}
\hline \multirow{2}{*}{ Facets } & \multicolumn{3}{|c|}{ Others } & \multicolumn{3}{|c|}{ Meditators } & \multirow[b]{2}{*}{$p$} \\
\hline & Median & Mean & SD & Median & Mean & SD & \\
\hline FFMQ total* & 124.00 & 124.52 & 16.48 & 153.00 & 152.25 & 12.38 & 0.000 \\
\hline Nonjudge* & 28.00 & 26.32 & 8.20 & 32.00 & 32.36 & 4.11 & 0.001 \\
\hline Act with Awareness (automatic pilot)** & 18.00 & 17.81 & 2.82 & 20.00 & 19.58 & 1.84 & 0.008 \\
\hline Observe** & 21.00 & 21.71 & 7.31 & 28.00 & 27.11 & 3.93 & 0.001 \\
\hline Describe (positive)** & 16.00 & 15.23 & 4.95 & 20.00 & 19.08 & 4.36 & 0.002 \\
\hline Describe (negative)** & 12.00 & 11.48 & 3.13 & 14.00 & 13.58 & 2.08 & 0.003 \\
\hline Nonreact** & 22.00 & 21.48 & 4.60 & 30.00 & 28.31 & 5.27 & 0.000 \\
\hline Act with Awareness (distraction)* & 11.00 & 10.48 & 3.26 & 12.00 & 12.22 & 1.90 & 0.012 \\
\hline
\end{tabular}

Notes: $* p<0.05 \mathrm{t}$ test for independent samples; $* * p<0.05$ Mann-Whitney test

women, ages ranging from up to 44 years old, family incomes above three times the minimum wage, and at least started college education.

For all facets of FFMQ-BR and its total score, there was a significant difference between the groups indicating that the questionnaire could adequately differentiate the levels of mindfulness among the population of meditators who presumably would have a higher level of mindfulness (Table 4).

\section{Reliability - FFMQ-BR}

The Cronbach's alpha of the total scale was 0.81 and the values of the alphas of the facets were: "nonjudge" $(\alpha=0.78)$, "Act with Awareness - Autopilot" $(\alpha=0.79)$, "Observe" ( $\alpha$ $=0.76)$, "Describe - positive items" $(\alpha=0.76)$, "Describe negative formulation items" ( $\alpha=0.75)$, "Noreact" $(\alpha=0.68)$, and "Act with Awareness - distraction" ( $\alpha=0.63)$.

The values of all test-retest correlations were significant, with $\mathrm{p}$ values < 0.001: Total FFMQ (0.90), "Nojudge" (0.80), "Act with Awareness - Autopilot" (0.67), "Observe" (0.83), "Describe - items with positive formulation" $(0.85)$, "Describe - items with negative formulation" (0.71), "Nonreact" (0.72), and "Act with Awareness - distraction" (0.80).

Following the steps made in the original validation paper in English (Baer et al., 2006) and seeking further evidence that the facets do not have overlapping content, we conducted a regression analysis for each facet in which the others were added as predictors. The adjusted R2 values ranged between 0.24 and 0.40 . Subtracting the value of adjusted $\mathrm{R}^{2}$ values from Cronbach's alpha of each facet, we obtained the systematic variance of the facet, regardless of their relationship with others. These values ranged from 0.36 to 0.52 , indicating a moderate portion of the variance in each facet being different from the others.

\section{Discussion}

The present data demonstrated that the methodology proposed by Beaton et al. (2002) proved consistent to support the steps of translation and adaptation of the FFMQ-BR systematically. The semantic equivalence criteria were carefully analyzed especially considering the need to keep it consistent with the Brazilian context and understandable to the respondents.

Regarding the sample, there was a great diversity of socio-demographics characteristics, which constitutes one of the strengths of this study, because it allows the instrument to be used by a greater number of people.

Concerning the psychometric properties of FFMQ$\mathrm{BR}$, the instrument showed satisfactory levels of validity and reliability. From the EFA, it was observed that the questionnaire in its Brazilian version behaved in a different way when compared to the original version in English (Baer et al., 2006), comprised of seven factors. Despite this difference, the evidence regarding the construct validity of the FFMQ-BR has been confirmed since the new factor structure considerably explained the total variance of the scale $(49.56 \%)$, even greater than the variance explained by the structure of the five factors in its original version, which was 33\% (Baer et al., 2006). Moreover, the values of the items factor loadings were satisfactory with an average of 0.58 , in comparison with the other validations, wherein the factor loadings ranged from 0.31 to 0.92 (Christopher, Neuser, Michael, \& Baitmangalkar, 2012; Tran et al., 2013; Veehof et al., 2011). The version with the seven factors was given by dividing two of the original factors into other two parts, and was approved by the author of the original instrument. Furthermore, it was observed that the facets, which split showed significant correlations between their new factors, indicating that although refer to formulations (in the case of "describe") or to different behavior (in the case of "act with awareness"), represented similar concepts.

The factor "Describe" split probably due to the formulation of the items, were positive in the fourth factor and negative in the fifth. It is common that the cultural adaptation and the way the items were formulated, positively or negatively, bring biases and possibly change the metric properties of the instruments. These factors stress the need 
for extreme attention to build tools to avoid problems like this (Maroco, Tecedeiro, Martins, \& Meireles, 2008).

Considering the "Act with Awareness" facet, there was a clear division between items that referred to the behavior of acting on autopilot and the ones related to the behavior of acting distractedly. This division could be due to the fact that while acting distractedly, the person uses vigilant attention and not having a specific focus, whereas acting on autopilot, the individual has a focus on their task, but both behaviors were not accompanied by consciousness. Another study found results that support this explanation, suggesting that focused and distributed attention produce different effects on consciousness (Baijal \& Sirinivasan, 2009).

Moreover, the practice of mindfulness meditation involves brain areas involved in vigilance, monitoring and disengagement of attention from distracting sources during the streaming of experience. Thus, the cultivation of this reflective consciousness through meditation is associated with a more vivid conscious access to the features of each experience and with the improvement of the metaconsciousness and self-regulation skills (Lutz et al., 2008).

The differences in the values of the factor loadings, in the variance explanation, and in the dimensionality of the FFMQ-BR, compared to its original version, may be due to the difficulty of the non-meditators in understanding terms referring to mindfulness, or due to the difference in interpretation between them and the meditators regarding those terms, which are part of everyday life and are best understood by people who practice meditation.

Still, considering the construct validity, the FFMQBR correlated positively and significantly with the PWBS, considering both their total score and its facets. The correlations between the mindfulness measures and the PWBS were moderate, as expected, indicating that mindfulness and subjective well-being are related concepts and can influence each other, but refer to different concepts.

These results indicate that the development of mindfulness skills can contribute to the improvement of mental health, particularly with regard to their influence on subjective wellbeing and emotion regulation (Keng, Smoski, \& Robins, 2011). From this point of view, it is important to consider the multidimensionality of the concept once prior studies found results indicating the role of specific abilities in emotion regulation. Specifically, the present-moment awareness and nonjudgmental acceptance are crucial in promoting executive control because they increase sensitivity to affective cues in the experiential field. This refined attunement and openness to subtle changes in affective states foster executive control because it improves response to incipient affective cues that help signal the need for control. This, in turn, enhances emotion regulation and consequently subjective well-being (Teper, Segal, \& Inzlicht, 2013).

We observed that all facets of FFMQ-BR correlated significantly with its total score, indicating that each of them contributes to the construct of mindfulness functioning as components of this construct. With regard to the correlation between the facets, there was a weak but negative correlation between the facets "Nonjudge" and "Observe." This result was also found in the validation study of KIMS and the original FFMQ (Baer, Smith, \& Allen, 2004; Baer et al., 2006). As the argument used by these authors, this result may be due to lack of practice in meditation of the vast majority of study participants. According to these authors, for individuals without meditation practice it is difficult to observe the events and mental events without making judgments.

With respect to the analysis performed and in order to find evidence of criterion validity, it was observed that in the FFMQ-BR the total scores and the scores of each facet were significantly higher among meditators than among other participants. This indicates that the FFMQ-BR was able to differentiate between people with meditation practice, which presumably should have higher levels of mindfulness and individuals without practice. These results are consistent with the existing literature, which indicates higher levels of mindfulness, self-compassion and general well-being as well as significantly lower levels of psychological symptoms, rumination, thought supression, fear of emotions and difficulties in emotional regulation among meditators when compared with the population that do not meditate (Lykins \& Baer, 2009).

With regard to the results of reliability of the FFMQ-BR, one of the strengths of this study was to use more than one method to assess its reliability, once each of them inherently bring possibilities of error and are influenced by other factors (Maroco et al., 2008). The reliability of the FFMQ-BR could be considered high, since it had high levels of testretest correlations showing that the FFMQ-BR remains a reliable measure of mindfulness through time. Moreover, it had an alpha of 0.81 for the total score and the alphas of the facets ranging from 0.63 to 0.79 . The only two facets with alphas lower than 0.7 were "Nonreact" $(\alpha=0.68)$ and "Act with Awareness - distraction" ( $\alpha=0.63)$. However, these values were expected since the first has three items with factor loadings $<0.4$ and the facet "Acting with Awareness - distraction" consists of only three items, which may have contributed to this reduced alpha value.

Besides the reasons already presented above, the reduced alpha value of the "Nonreact" facet may have occurred because its initial validation was composed mainly by the Freiburg Mindfulness Inventory items-FMI. This instrument was originally built for a population of meditators (Buchheld, Grossman, \& Walach, 2001), so its items cannot be adequately understood by the general population or by people who do not practice meditation, which is the case for most of the participants of this study, as explained above.

This study provided important results concerning the study of scales that aim to assess trait mindfulness, which may also help in the operationalization of this concept. Also, it can be considered a pioneer in a recent line of studies that aim to test the psychometric properties of these instruments in a demographically diverse population.

Besides the strengths of this study, it also has some limitations. There is a need of complementary investigations similar to the confirmatory factorial analysis and the utilization of analysis with more consistent methods, such as policoric factorial analysis and the Item Response Theory with larger samples. Also, multiple regression analysis that consider other mindfulness related constructs are needed to explore the implications of this construct in the mental 
health field, in the emotion regulation, and in the cognitive functioning in order to contribute a better understanding of the human behavior.

\section{Conclusion}

The study achieved the goals of adapting and evaluating the psychometric properties of FFMQ-BR and converting it into an appropriate tool to measure trait mindfulness among psychology students, smokers, Brazilian meditators, and general population. This study may help in providing subsidies to the progress of research in this area by examining the empirical relationships between mindfulness and mental health. This study provided initial evidence that mindfulness is positively associated with subjective wellbeing and suggests that this construct has promising role for future etiologic studies. However, it is important that these instruments continue to be tested for its psychometric properties in different populations and sociocultural contexts of Brazilian reality.

The validation and adaptation of the instrument (FFMQ) for the Brazilian population might represent an important step towards the identification of specific results of mindfulness practices and their differentiation from pre-existing attributes, thus allowing researchers to have a more precise conception of the abilities actually developed in this meditation modality.

\section{References}

Albuquerque, A. S., \& Tróccoli, B. T. (2004). Desenvolvimento de uma escala de bem-estar subjetivo. Psicologia Teoria e Pesquisa, 20, 153-164. doi:10.1590/S0102-37722004000200008

Baer, R. A. (2011). Measuring Mindfulness. Contemporary Buddhism, 12, 241-261. doi: 10.1080/14639947.2011.564842

Baer, R. A., Smith, G. T., \& Allen, K. B. (2004). Assessment of mindfulness by report. The Kentucky inventory of mindfulness skills. Assessment, 11(3), 191-206.

Baer, R.A., Smith, G. T., Hopkins, J., Krietemeyer, J., \& Toney, L. (2006). Using self-report assessment methods to explore facets of mindfulness. Assessment, 13(1), 27-45.

Baer, R. A., Smith, G. T., Lykins, E., Button, D., Krietemeyer, J., Sauer, S., . . . Williams, J. M. (2008). Construct validity of the five facet Mindfulness Questionnaire in Meditating and Nonmeditating Samples. Assessment, 15, 329-342. doi: $10.1177 / 1073191107313003$

Baijal, S., \& Srinivasan, N. (2009). Types of Attention Matter For Awareness: A study with color afterimages. Consciousness and Cognition, 18(4), 1039-1048.

Beaton, D., Bombardier, C., Guillemin, F., \& Ferraz, M. B. (2002). Recommendations for the cross-cultural adaptation of Health Status Measures. Rosemont, IL: American Academy of Orthopaedic Surgeons Institute for Work \& Health.

Buchheld, N., Grossman, P., \& Walach, H. (2001). Measuring mindfulness in insight meditation (vipassana) and meditationbased psychotherapy: The Development of the Freiburg Mindfulness Inventory (FMI). Journal for Meditation and Meditation Research, 1(1), 11-34.
Carlson, L. E., Speca, M., Patel, K. D., \& Goodey, E. (2004). Mindfulness-based stress reduction in relation to quality of life, mood, symptoms of stress and levels of cortisol, dehydroepiandrosterone sulfate (DHEAS) and melatonin in breast and prostate cancer outpatients. Psychoneuroendocrinology, 29(4), 448-474.

Carmo, J. T. d., \& Pueyo, A. A. (2002). A adaptação ao português do Fagerström test for nicotine dependence (FTND) para avaliar a dependência e tolerância à nicotina em fumantes brasileiros. RBM: Revista Brasileira de Medicina, 58(1/2), 73-80.

Cebolla, A., García-Palacios, A., Soler, J., Guillen, V., Baños, R., $\&$ Botella, C. (2012). Psychometric properties of the Spanish validation of the Five Facets of Mindfulness Questionnaire (FFMQ). European Journal of Psychiatry, 26, 118-126. doi: $10.4321 / \mathrm{S} 0213-61632012000200005$

Chiesa, A. \& Serretti, A. (2010). A systematic review of neurobiological and clinical features of mindfulness meditations. Psychological Medicine, 40, 1239-1252. doi: 10.1017/S0033291709991747

Chiesa, A., \& Serretti, A. (2014). Are Mindfulness-Based Interventions Effective for Substance Use Disorders? A Systematic Review of the Evidence. Substance Use \& Misuse. Advance online publication. doi:10.3109/10826084.2013.7 70027

Christopher, M. S., Neuser, N. J., Michael, P. G., \& Baitmangalkar, A. (2012). Exploring the Psychometric Properties of the Five Facet Mindfulness Questionnaire. Mindfulness, 3, 124-131. doi: 10.1007/s12671-011-0086-x

Didonna, F. (2009). Clinical Handbook of Mindfulness. New York, NY: Springer.

Dimidjian, S., \& Linehan, M. M. (2003). Mindfulness Practice. In W. O’Donohue, J. E. Fisher, \& S. C. Hayes (Eds.), Empirically Supported Techniques of Cognitive Behavior Therapy: A stepby-step Guide for Clinicians (pp. 229-237). New York, NY: John Wiley.

Dundas, I., Vøllestad, J., Binder, P.-E., \& Sivertsen, B. (2013). The Five Factor Mindfulness Questionnaire in Norway. Scandinavian Journal of Psychology, 54, 250-260. doi: 10.1111/sjop. 12044

Gross, C. R., Kreitzer, M. J., Reilly-Spong, M., Wall, M., Winbush, N. Y., Patterson, R., ... \& Cramer-Bornemann, M. (2011). Mindfulness-based stress reduction versus pharmacotherapy for chronic primary insomnia: a randomized controlled clinical trial. Explore (NY), 7, 76-87. doi: 10.1016/j. explore.2010.12.003

Hair, J. F., Anderson, R. E., Thatan, R. L. \& Black, W. C. (2005). Análise Multivariada de Dados (A. S. Sant'Anna \& A. Chaves Neto, Trads., $5^{\text {a }}$ ed.). Porto Alegre, RS: Artmed, 2005.

Hölzel, B. K., Lazar, S. W., Gard, T., Schuman-Olivier, Z., Vago, D. R., \& Ott, U. (2011). How does mindfulness work? Proposing mechanisms of action from a conceptual and neural perspective. Perspectives on Psychological Science, 6, 537559. doi: 10.1177/1745691611419671

Hou, J., Wong, S. Y., Lo, H. H., Mak, W. W., \& Ma, H. S. (2013). Validation of a Chinese Version of the Five Facet Mindfulness Questionnaire in Hong Kong and Development of a Short Form. Assessment. Advance online publication. doi: $10.1177 / 1073191113485121$ 
Kabat-Zinn, J. (1990). Full Catastrophe Living: Using the Wisdom of Your Body and Mind to Face Stress, Pain, and Illness. New York, NY: Delta.

Keng, S. L., Smoski, M. J., \& Robins, C. J. (2011). Effects of mindfulness on psychological health: A review of empirical studies. Clinical Psychology Review, 31, 1041-1056. doi: 10.1016/j.cpr.2011.04.006

Lutz, A., Slagter, H. A., Dunne, J. D., \& Davidson, R. J. (2008). Attention regulation and monitoring in meditation. Trends in Cognitive Sciences, 12, 163-169. doi: 10.1016/j. tics.2008.01.005

Lykins, E., \& Baer, R. A. (2009). Psychological functioning in a sample of long-term practitioners of mindfulness meditation. Journal of Cognitive Psychotherapy, 23, 226-241. doi: 10.1891/0889-8391.23.3.226

Maroco, J., Tecedeiro, M., Martins, P., \& Meireles, A. (2008). O Burnout como factor hierárquico de $2^{\mathrm{a}}$ ordem da Escala de Burnout de Maslach. Análise Psicológica, 26(4), 639-649.

Morone, N. E., Lynch, C. S., Greco, C. M., Tindle, H. A., \& Weiner, D. K. (2008). "I felt like a new person." the effects of mindfulness meditation on older adults with chronic pain: qualitative narrative analysis of diary entries. The Journal of Pain, 9, 841-848. doi: 10.1016/j.jpain.2008.04.003

Nesvold, A., Fagerland, M. W., Davanger, S., Ellingsen, O., Solberg, E. E., Holen, A., . . . Atar, D. (2012). Increased heart rate variability during nondirective meditation. European Journal of Preventive Cardiology, 19, 773-780. doi: $10.1177 / 1741826711414625$

Sauer, S., Walach, H., Schmidt, S., Hinterberger, T., Lynch, S., Büssing, A., \& Kohls, N. (2013). Assessment of Mindfulness: Review on State of the Art. Mindfulness, 4(1), 3-17. doi: 10.1007/s12671-012-0122-5

Schroevers, M. J., \& Brandsma, R. (2010). Is learning mindfulness associated with improved affect after mindfulness-based cognitive therapy? British Journal of Psychology, 10, 95-107. doi: 10.1348/000712609X424195

Segal, Z. V., Williams, J. M. G., \& Teasdale, J. D. (2002). Mindfulness-based Cognitive Therapy for Depression: A New Approach to Preventing Relapse. New York, NY: Guilford.

Shapiro, S. L., Oman, D., Thoresen, C. E., Plante, T. G., \& Flinders, T. (2008). Cultivating mindfulness: Effects on well-being. Journal of Clinical Psychology, 64, 840-862. doi: 10.1002/ jclp.20491
Sugiura, Y., Sato, A., Ito, Y., \& Murakami, H. (2012). Development and Validation of the Japanese Version of the Five Facet Mindfulness Questionnaire. Mindfulness, 3, 85-94. doi: 10.1007/s12671-011-0082-1

Tácon, A. M., McComb, J., Caldera, Y., \& Randolph, P. (2003). Mindfulness meditation, anxiety reduction, and heart desease- a pilot study. Family \& Community Health, 26(1), 25-33.

Teasdale, J. D., Segal, Z., \& Williams, J. (1995). How does cognitive therapy prevent depressive relapse and why should attentional control (mindfulness) training help? Behaviour Research and Therapy, 33(1), 25-39.

Teper, R., Segal, Z. V., \& Inzlicht, M. (2013). Inside the Mindful Mind: How Mindfulness Enhances Emotion Regulation Through Improvements in Executive Control. Current Directions in Psychological Science. Advance online publication. doi: 10.1177/0963721413495869

Tran, U. S., Glück, T. M., \& Nader, I. W. (2013). Investigating the Five Facet Mindfulness Questionnaire (FFMQ): Construction of a Short Form and Evidence of a Two-Factor Higher Order Structure of Mindfulness. Journal of Clinical Psychology, 69, 951-965. doi: 10.1002/jclp.21996

Veehof, M. M., Klooster, P. M., Taal, E., Westerhof, G. J., \& Bohlmeijer, E. T. (2011). Psychometric properties of the Dutch Five Facet Mindfulness Questionnaire (FFMQ) in patients with fibromyalgia. Clinical Rheumatology, 30, 1045-1054. doi: 10.1007/s10067-011-1690-9

Williams, J. M. G. (2008). Mindfulness, depression and modes of mind. Cognitive Therapy and Research, 32, 721-733. doi: 10.1007/s10608-008-9204-Z

Witkiewitz, K., Marlatt, G. A., \& Walker, D. (2005). Mindfulnessbased relapse prevention for alcohol and substance use disorders. Journal of Cognitive Psychotherapy, 19, 211-228. doi: $10.1891 /$ jcop.2005.19.3.211

Recebido em 26.11.2012

Primeira decisão editorial em 11.11.2013

Versão final em 18.12.2013

Aceito em 10.02.2014 